\title{
Molecular signature of active fibrogenesis prevails in biliary atresia after successful portoenterostomy
}

\section{Kerola, Anna}

2017-09

Kerola , A , Lampela , H , Lohi , J , Heikkilä , P , Mutanen , A, Jalanko , H \& Pakarinen , M P 2017 , ' Molecular signature of active fibrogenesis prevails in biliary atresia after successful portoenterostomy ' , Surgery , vol. 162 , no. 3 , pp. 548-556 . https://doi.org/10.1016/j.surg.2017.04.013

http://hdl.handle.net/10138/297939

https://doi.org/10.1016/j.surg.2017.04.013

publishedVersion

Downloaded from Helda, University of Helsinki institutional repository.

This is an electronic reprint of the original article.

This reprint may differ from the original in pagination and typographic detail.

Please cite the original version. 


\title{
Molecular signature of active fibrogenesis prevails in biliary atresia after successful portoenterostomy
}

\author{
Anna Kerola, MD, ${ }^{\text {a,b }}$ Hanna Lampela, MD, PhD,,${ }^{\text {cd }}$ Jouko Lohi, MD, PhD, ${ }^{\text {e }}$ Päivi Heikkilä, MD, PhD, \\ Annika Mutanen, MD, PhD, ${ }^{\mathbf{a}}$ Hannu Jalanko, MD, PhD, ${ }^{\mathbf{f}}$ and Mikko P. Pakarinen, MD, PhD, ${ }^{\mathbf{a}}$ Helsinki \\ and Joensuu, Finland
}

Background. In biliary atresia mechanisms of progressive liver injury leading to need of liver transplantation after successful portoenterostomy remain unknown. A better understanding is a prerequisite for development of novel therapies to extend native liver survival, and we aimed to unravel molecular characteristics of liver injury after successful portoenterostomy.

Methods. Liver biopsies obtained from 28 biliary atresia children during successful portoenterostomy and at median age 3.0years were studied. Biopsies were analyzed for histology and immunohistochemical expression of collagen 1, myofibroblast marker $\alpha$-smooth muscle actin, and cytokeratin-7 positive ductal reactions. Hepatic ribonucleic acid (RNA) expression of growth factors and inflammatory cytokines was evaluated. Intestinal failure patients with comparable liver fibrosis and nonfibrotic gallstone patients and donor livers were controls. Results. After successful portoenterostomy, histologic cholestasis resolved and portal inflammation reduced, while fibrosis along with ductal reactions and overexpression of collagen and $\alpha$-smooth muscle actin persisted. At follow-up, liver RNA expression of collagen and platelet-derived growth factor was increased, whereas RNA expression of various inflammatory cytokines remained low. Disappearance of periductal $\alpha$ smooth muscle actin expression after successful portoenterostomy (36\% of patients) associated with contracted ductal reactions and reduced progression of fibrosis, collagen accumulation, platelet-derived growth factor RNA expression, and serum levels of bile acids and bilirubin. Fibrosis progressed less rapidly in syndromic than in isolated biliary atresia patients.

Conclusion. These findings suggest that instead of inflammation, molecular signature of active fibrogenesis in association with ductal reactions prevails in long-term native liver survivors with biliary atresia. Patients should be stratified for isolated and syndromic disease forms in interventional studies. (Surgery 2017;162:548-56.)

From the Pediatric Surgery and Pediatric Transplantation Surgery, ${ }^{a}$ Pediatric Liver and Gut Research Group, Children's Hospital, Pediatric Liver and Gut Research Group, ${ }^{d}$ Children's Hospital, Pathology, ${ }^{e}$ and Pediatric Nephrology and Transplantation, ${ }^{f}$ University of Helsinki and Helsinki University Hospital, Helsinki, Finland; Department of Surgery, ${ }^{b}$ North Karelia Central Hospital, Joensuu, Finland; Gastrointestinal Surgery, ${ }^{c}$ HUH Abdominal Center, Helsinki University, Helsinki, Finland

BiLIARY ATRESIA (BA) is a destructive fibroinflammatory cholangiopathy of infancy and the most frequent indication for pediatric liver transplantation (LTx)

Supported with research grants by the Finnish Pediatric Research Foundation, Sigrid Juselius Foundation, and the Research Foundation of Helsinki University Hospital. The work was independent of the funding.

Accepted for publication April 20, 2017.

Reprint requests: Anna Kerola, MD, Biomedicum 2 C 609, PL 705, 00290 HUS, Helsinki, Finland. E-mail: anna.kerola@ helsinki.fi.

0039-6060/\$ - see front matter

(c) 2017 Elsevier Inc. All rights reserved.

http://dx.doi.org/10.1016/j.surg.2017.04.013 worldwide. ${ }^{1-3}$ Viral infection induced aberrant immune response, defective morphogenesis, and environmental toxins are the most commonly cited etiological factors, although the pathogenesis remains unresolved. ${ }^{1-5}$ Excluding LTx, portoenterostomy (PE) is the only effective therapy available. Despite reestablishment of bile flow by PE in $\leq 75 \%$ of patients, ${ }^{6}$ a vast majority will require LTx by adulthood due to evolving liver injury.

Mechanisms of continuing liver injury after successful PE (SPE) despite resolution of cholestasis remain unknown. ${ }^{1}$ Better understanding of these mechanisms is essential for development of novel medical therapies to extend native liver survival. One possibility would be preventing 
progression of liver injury after SPE in similar fashion to what has been demonstrated recently for farnesoid X receptor agonists in adults with nonalcoholic steatohepatitis and primary biliary cirrhosis. ${ }^{9,10}$ As effective prevention of BA seems unlikely in the foreseeable future, strategies to delay the need for LTx after PE have emerged as the key issues in the field. ${ }^{11}$

Activation of portal fibroblasts and hepatic stellate cells (HSCs) into collagen-producing and $\alpha$-smooth muscle actin ( $\alpha$-SMA) expressing myofibroblasts plays a crucial role in liver fibrogenesis. ${ }^{12,13}$ Reactive biliary epithelial cells of ductal reactions, the characteristic proliferation of bile ductules in response to cholestasis, may be particularly important mediator of liver fibrogenesis in BA through metaplasia, although the exact source of these cells remains unclear. ${ }^{14-16}$ Expansion of cytokeratin-7 (CK-7) positive ductal reactions associate with decreased native liver survival, progressive fibrosis, and increased expression of matrix metalloproteinase-7. ${ }^{17-19}$ Increased hepatic expression of collagen 1 and $\alpha$-SMA at time of PE correlates with reduced native liver survival. $^{20,21}$ Platelet-derived growth factor (PDGF) is probably the most potent mitogen for myofibroblasts and is markedly upregulated during liver fibrogenesis. ${ }^{12,13,22}$

This study aimed to explore molecular characteristics of liver injury following SPE, when the patients are not cholestatic and display mostly intermediate stage of liver fibrosis exhibiting the greatest potential for its efficacious manipulation. We hypothesized that the livers of long-term survivors after SPE display a molecular signature of active fibrogenesis despite limited inflammation. For this, we assessed liver histology as well as protein and gene expression of profibrotic and inflammatory mediators in BA patients during and after SPE in relation to fibrotic and nonfibrotic controls. As isolated and syndromic BA patients most likely have diverse etiologies, we also compared progression of fibrosis between these subgroups.

\section{MATERIALS AND METHODS}

Patients and controls. In Helsinki University Hospital of Finland, 51 BA patients were treated between 1991 and 2013. Thirty (59\%) normalized serum bilirubin below $20 \mu \mathrm{mol} / \mathrm{L}$ after SPE, and $28(93 \%)$ were enrolled. They underwent serum sampling and liver biopsy as described previously. ${ }^{19}$ Liver biopsies from 11 intestinal failure patients with associated liver fibrosis (median age 4.7 [interquartile range 3.5-9.7] years) were used as diseased controls. Nonfibrotic control liver tissue was obtained from 10 children with median age 11.4 years (7.8-14.8), who had undergone core needle liver biopsy as a part of research protocol (434/13/03/03/2008) during operative treatment of cholecystolithiasis and from 19 donor livers (median age 14.2 [8.016.2] years).

Clinical data. Serum samples were analyzed for platelets, total and direct bilirubin, bile acids, alanine aminotransferase (ALT) and aspartate aminotransferase (AST). AST to platelet ratio index (APRI) was calculated as follows: (AST, U/ L) /50)/platelet count (E9/L)] x $100 .{ }^{23}$ Syndromic BA was defined by the presence of any associated congenital structural malformation and BA splenic malformation (BASM) was defined as the presence of poly- or asplenia. ${ }^{24}$

Liver histology and immunohistochemistry. Percutaneous core needle liver biopsies were obtained under ultrasound guidance as a part of the follow-up protocol when patients were anesthetized for endoscopic variceal surveillance. No biopsy-related complications were recorded. Biopsies were fixed in formalin, embedded in paraffin, sliced, and stained as described previously. ${ }^{19}$ Twenty-four operative wedge liver biopsies obtained at PE and 28 core needle follow-up biopsies were analyzed semiquantitatively by 2 experienced pediatric liver pathologists blinded to clinical data. Fibrosis was analyzed according to the Metavir fibrosis stage $(0=$ no fibrosis, $1=$ fibrous expansions of portal areas, $2=$ portal-to-portal fibrosis, 3 = portal-to-portal and portal-to-central fibrosis, or $4=$ cirrhosis). Portal inflammatory cell infiltration and intracanalicular cholestasis were graded as $0=$ absent or minimal, $1=$ mild, 2 = moderate, or 3 = marked.

Monoclonal antibodies for immunostaining were clone I-8H5 (Abnova corporation, Taipei City, Taiwan) for collagen 1 and clone 1A4 (DakoCytomation, Glostrup, Denmark) for $\alpha$-SMA. Immunostaining for CK-7 was performed using a rabbit antihuman monoclonal antibody and ultraView Universal DAB Detection kit (Ventana, Tucson, AZ). Core needle biopsies were photographed as a whole and 5 random images from wedge biopsies were taken matching the surface area of core needle biopsies. The proportion of the antibody-positive area to the whole surface area of the biopsy (area fraction) was calculated for CK-7, collagen 1, and $\alpha$-SMA with Image (Bethesda, MD) Image Analysis Software (SciJava Common open source software). Ductal reaction was visualized by CK-7 expression in proliferative bile ductules, 
adjacent periportal hepatocytes, and bile ducts. Leica DM RXA microscope (Leica Microsystems $\mathrm{GmbH}$, Wetzlar, Germany) was used for grading of immunostainings, which were performed by primary author (A.K.), blinded to clinical data. Localization and intensity of immunostaining were analyzed semiquantitatively; collagen 1 : $0=$ slight expression at portal areas, $1=$ expanded expression at portal areas, 2 = portal-to-portal, and 3 = portal-to-central, or $4=$ extended nodular expression (cirrhosis). $\alpha$-SMA: $0=$ staining in smooth muscle cells within portal vessel walls only, $1=$ mild or moderate periportal expression with 2 = mild or moderate, or 3 = strong bridging between portal tracts, $4=$ marked portal expression in the entire portal area with portal bridging (modified from Olynyk et $\mathrm{al}^{25}$ ). Periductal $\alpha$-SMA staining surrounding bile ducts and ductal proliferations was analyzed dichotomously.

Ribonucleic acid expression analyses. Liver tissue specimens were embedded in ribonucleic acid (RNA) later-solution (Ambion, Life technologies, Thermo Fisher Scientific Inc, Waltham, MA) and frozen. RNeasy Mini Kit (QIAGEN, Frederick, MD) was used to extract RNA. Integrity of RNA was determinated spectrophotometrically. Human Fibrosis $\mathrm{RT}^{2}$ Profiler PCR Array (QIAGEN SABiosciences, Frederick, MD) on an ABI 7700 Sequence Detection System (Perkin-Elmer Life Sciences, Boston, MA) was used to analyze RNA expression in triplicate by quantitative real-time polymerase chain reaction according to the manufacturer's instructions. Quantification of target gene mRNA expression was performed using the $\Delta \Delta \mathrm{Ct}$ method and expressed after normalization to housekeeping genes (B2M, HPRT1, RPL13A, GAPDH, $A C T B$ ) and relative to control subjects.

Ethics. Study protocol was approved by the Ethics Committee of the Hospital District of Helsinki and Uusimaa (number 345/13/03/03/ 2008), and observing the ethical guidelines of the 1975 Declaration of Helsinki. Informed consent in writing was obtained from legal guardians of all participating children.

Statistical analysis. Statistical analysis was performed using SPSS software version 22.0 for Windows (IBM Corp., Armonk, NY). All data are median (interquartile range) unless otherwise stated. Continuous variables were compared using the Mann-Whitney $U$ test or Wilcoxon signed-rank test when appropriate. Dichotomous variables were compared using Fisher exact test or McNemar test. Correlations were calculated using Spearman's rank correlation.

\section{RESULTS}

Patient characteristics. Median age was 61 (4084) days at PE and 3.0 (2.1-6.7) years at follow-up. Half of the patients were males and 12 (43\%) had associated structural anomalies, including cardiac defects (at least a septal defect; $n=8$ ), polysplenia $(n=8)$, vascular anomalies $(n=4)$, intestinal malrotation $(n=5)$, pancreatic anomalies $(n=3)$, and situs inversus $(n=1)$. One patient had Sotos syndrome, a rare genetic disorder with excessive physical growth and mild intellectual disability. Eight patients (29\%) had BASM. At follow-up 32\% had splenomegaly, and $50 \%$ had developed clinical signs of portal hypertension.

Evolution of liver histology and ductal reaction after successful PE. Liver histology and biochemistry at PE and at follow-up are shown in Table I. After PE, histologic cholestasis and hyperbilirubinemia resolved and portal inflammation significantly reduced, while Metavir fibrosis stage and the magnitude of ductal reactions remained unchanged.

Immunohistochemistry of profibrotic and endothelial markers. Liver expression of collagen 1 and $\alpha$-SMA in BA patients, intestinal failure controls with comparable Metavir fibrosis stage and donor liver controls without fibrosis are shown in Table II. BA patients showed markedly increased collagen and $\alpha$-SMA expression compared with control donor livers. Collagen area fraction and $\alpha$-SMA grading were significantly greater in BA patients than in intestinal failure controls. Collagen expression was comparably increased in the portal areas of BA patients and intestinal failure controls, but more extensive bridging between portal and central areas was observed in BA, explaining the greater area fraction in BA. Because localization and intensity of $\alpha$-SMA staining concentrated more to portal and periductal areas in BA patients than in intestinal failure patients, no statistical difference in $\alpha$ SMA area fraction was observed between the groups despite increased $\alpha$-SMA grade in BA. Indeed, as shown in Table II and Fig, none of the fibrotic controls showed periductal $\alpha$-SMA expression, compared with $100 \%$ of BA patients at SPE and $64 \%$ at follow-up ( $P=.001$ versus controls).

At follow-up, the magnitude of ductal reactions correlated positively with the degree of $\alpha$-SMA $(\mathrm{r}=0.650, P=.001)$ and collagen expression $(\mathrm{r}=0.553, P=.003)$, while expression of collagen and $\alpha$-SMA were interrelated $(\mathrm{r}=0.812$, $P<.001)$. Notably, the age at follow-up was unrelated to expression of collagen $1(\mathrm{r}=-0.085$, $P=.667)$ or $\alpha$-SMA $(\mathrm{r}=-0.129, P=.539)$. 
Table I. Liver histology and biochemistry in biliary atresia patients at PE and after a median follow-up of 3.0 years

\begin{tabular}{lcccr}
\hline & Scale/Unit & $\mathrm{n}=24$ & $\begin{array}{c}\text { Follow-up } \\
\mathrm{n}=28\end{array}$ & $\mathrm{P}$ value \\
\hline Liver histology & & & & \\
$\quad$ Metavir fibrosis stage & $0-4$ & $2(2-3)$ & $2(1-4)$ & .170 \\
Intracanalicular cholestasis & $0-3$ & $2(1-3)$ & $0(0-0)$ & $<.001$ \\
$\quad \begin{array}{l}\text { Portal inflammatory cell infiltrate } \\
\text { Ductal reaction }\end{array}$ & $0-3$ & $2(2-3)$ & $1(0-1)$ & $<.001$ \\
Liver biochemistry & $\%$ & $5.0(3.3-7.0)$ & $2.4(1.8-4.9)$ & .227 \\
$\quad$ Bilirubin total & $\mu \mathrm{mol} / \mathrm{L}$ & $159(116-204)$ & $10(4-17)$ & $<-801$ \\
Bilirubin direct (conjugated) & $\mu \mathrm{mol} / \mathrm{L}$ & $115(83-159)$ & $4(2-8)$ & $<.001$ \\
Bile acids, total & $\mu \mathrm{mol} / \mathrm{L}$ & $143(73-197)$ & $32(16-92)$ & $\mathbf{. 0 4 9}$ \\
ALT & $\mathrm{U} / \mathrm{L}$ & $87(42-164)$ & $45(24-94)$ & $\mathbf{. 0 1 2}$ \\
APRI* & & $0.83(0.42-1.41)$ & $1.18(0.45-1.95)$ & .551 \\
\hline
\end{tabular}

*APRI, [(aspartate aminotransferase $($ AST, U/L)/50)/platelet count $(\mathrm{E} 9 / \mathrm{L})] \times 100$.

Data are median (interquartile range). Significance was evaluated by Wilcoxon signed-rank test. Bolded $P$-values mean that they are statistically significant $(P<.05)$.

Table II. Histologic liver fibrosis and immunohistochemistry of fibrogenic markers in BA patients at PE and after a median follow-up of 3.0 years in relation to controls

\begin{tabular}{|c|c|c|c|c|c|}
\hline Variable & $\begin{array}{l}B A \text { at } P E \\
\mathrm{n}=24\end{array}$ & $\begin{array}{l}\text { BA at follow-up* } \\
\mathrm{n}=28\end{array}$ & $\begin{array}{l}\text { Intestinal failure controls } \\
\qquad \mathrm{n}=11\end{array}$ & $\begin{array}{l}\text { Donor liver } \\
\text { controls } \\
\mathrm{n}=19\end{array}$ & $\mathrm{P}$ value \\
\hline Metavir stage $(0-4)$ & $2(2-3)$ & $2(1-4) \dagger$ & $2(2-2) \S$ & $0(0-0)$ & $<.001$ \\
\hline Collagen, grade $(0-4)$ & $3(2-3)$ & $2(1-3) \dagger$ & $2(1-2) \S$ & $0(0-0)$ & $<.001$ \\
\hline Collagen, area fraction $(\%)$ & $17.4(12.6-22.4)$ & $15.6(10.0-22.5) \dagger, \ddagger$ & $6.8(5.9-7.5) \S$ & $3.5(2.3-4.2)$ & $<.001$ \\
\hline$\alpha$-SMA, grade $(0-4)$ & $3(2-3)$ & $2(1-4) \dagger, \ddagger$ & $0(0-0)$ & $0(0-0)$ & $<.001$ \\
\hline Periductal $(0-1)$ & $1(1-1)$ & $1(0-1) \dagger, \dagger$ & $0(0-0)$ & $0(0-0)$ & $<.001$ \\
\hline$\alpha$-SMA, area fraction $(\%)$ & $16.8(13.7-21.3)$ & $13.9(11.1-20.5) \dagger$ & $11.5(7.7-14.9) \S$ & $7.1(4.3-8.3)$ & $<.001$ \\
\hline
\end{tabular}

* Only significant difference in BA patients between portoenterostomy and follow-up was decline in periductal $\alpha$-SMA expression $(P=.016$ by McNemar test)

$\dagger P<.001$ compared with donor liver controls.

$\ddagger P<.001$ compared with intestinal failure controls.

$\S P<.035$ between intestinal failure and donor liver controls.

Data are median (interquartile range). Significance was evaluated for multiple groups by Kruskall-Wallis $\mathrm{H}$ test and for pairs of groups by Mann-Whitney $U$ test Bolded $P$-values mean that they are statistically significant $(P<.05)$

Hepatic expression of profibrotic and proinflammatory genes. Liver RNA expression of profibrotic and proinflammatory genes in BA patients at follow-up, fibrotic intestinal failure controls, and cholelithiasis controls without liver fibrosis are shown in Table III. Liver RNA expression of COL1A2 encoding for collagen 1 and PDGFA encoding for PDGF subunit A was significantly increased in BA compared with both control groups, while the increase in ACTA2 encoding for $\alpha$-SMA remained insignificant in relation to intestinal failure patients. In follow-up BA specimens, RNA expression of COL1A2 correlated positively with collagen $(\mathrm{r}=0.475, P=.019)$ and $\alpha$-SMA area fraction $(\mathrm{r}=0.512, P=.013)$, while PDGFA RNA expression correlated positively with collagen area fraction $(\mathrm{r}=0.673$, $P<.001)$ and $\alpha$-SMA grade $(\mathrm{r}=0.625, P=.002)$ and presence of periductal $\alpha$-SMA expression (Table IV).

Of the Th1 pro-inflammatory cytokine genes, RNA expression of $I L 1 A$ and $I L 1 B$ encoding for interleukin (IL)-1 did not differ between BA patients and nonfibrotic controls, but was even lower in BA patients than in intestinal failure controls. There were no differences between groups in RNA expression of $T N F$ and IFNG encoding for tumor necrosis factor and interferon gamma (Table III). Of the Th2 inflammatory cytokine genes, RNA expression of ILIO encoding for antiinflammatory IL-10 similarly decreased in BA and intestinal failure. RNA expression of IL4 and IL5 was comparable in different groups.

Periductal $\alpha$-SMA expression associated with ductal reaction and fibrosis. Periductal $\alpha$-SMA expression was observed in all patients at time of 

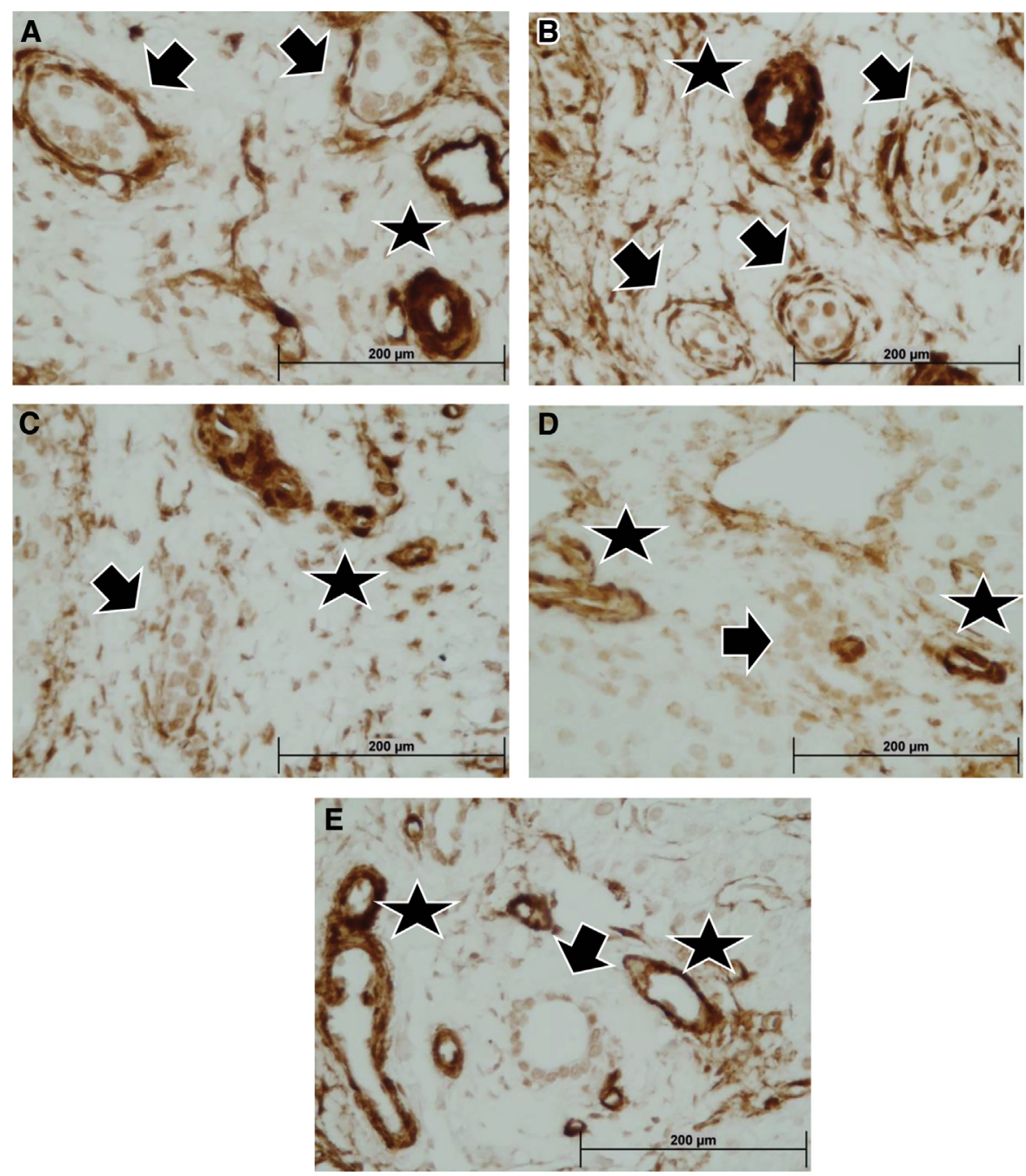

Fig. Periductal $\alpha$-SMA protein expression surrounding biliary epithelial cells (arrow) in patients and controls. The asterisk denotes staining of vessels at portal and fibrotic areas. All pictures $\times 400$. $(A)$ BA patient at portoenterostomy at age of 105 days. $(B)$ Same patient at 2.4 years of follow-up showing positive periductal staining. $(C)$ BA patient at 2.1 years of follow-up with negative staining. $(D)$ Fibrotic control. $(E)$ Nonfibrotic control.

PE and in $64 \%$ at follow-up $(P=.016)$. Patients, who continued to display periductal $\alpha$-SMA expression in the follow-up specimens, showed more progressive liver fibrosis after SPE (Metavir stage change $1[0$ to 2$]$ versus $0[-2$ to 0$], P=.054$ ) and expansion of the ductal reaction (Table IV). Patients with prevailing periductal $\alpha$-SMA expression also exhibited greater liver expression of collagen 1 and $\alpha$-SMA as well as greater serum levels of bile acids, conjugated bilirubin, ALT, and APRI than patients without (Table IV).

Distinct progression of liver fibrosis in patients with isolated and syndromic BA. The median Metavir fibrosis stage increased significantly after SPE in isolated (2 [2-3] versus 3 [2-4], $P=.026$ ), but not in syndromic (2 [2-3] versus 2 [1-2], $P=.579)$ BA patients (Table V). Follow-up Metavir stage, portal inflammatory cell infiltrate, and expression of collagen and $\alpha$-SMA were all significantly greater among isolated patients compared with syndromic ones. However, no significant differences were observed in gene expression of growth factors or inflammatory cytokines (data not shown). Patients with BASM tended to have lower Metavir fibrosis stage at follow-up than patients without, but the difference was not statistically significant (2 [1-2] vs $3[2-4], P=.072)$.

\section{DISCUSSION}

This is one of the first clinical studies characterizing molecular mechanisms associated with persistent liver injury following reversal of cholestasis by SPE. ${ }^{19}$ We discovered that despite resolution of inflammation, cholestasis and hyperbilirubinemia 
Table III. Liver expression of profibrotic and inflammatory mediator genes in biliary atresia patients after a median follow-up of 3.0 years in relation to controls

\begin{tabular}{|c|c|c|c|c|}
\hline Gene & $\begin{array}{l}\text { Biliaryatresia at follow-up } \\
\mathrm{n}=24\end{array}$ & $\begin{array}{l}\text { Intestinal failure controls } \\
\qquad \mathrm{n}=11\end{array}$ & $\begin{array}{l}\text { Cholelithiasis controls } \\
\mathrm{n}=10\end{array}$ & $\mathrm{P}$ value \\
\hline \multicolumn{5}{|l|}{ Fibrosis } \\
\hline COL1A2 & $2.72(1.81-3.58)^{*}, \dagger$ & $1.11(0.77-2.19)$ & $1.13(0.70-1.35)$ & $<.001$ \\
\hline ACTA2 & $1.57(1.09-2.66) *$ & $1.17(0.94-1.90)$ & $1.00(0.68-1.41)$ & .046 \\
\hline PDGFA & $3.12(2.02-5.43) *, \dagger$ & $1.35(0.82-1.92)$ & $1.08(0.63-1.30)$ & $<.001$ \\
\hline \multicolumn{5}{|c|}{ Inflammation } \\
\hline \multicolumn{5}{|c|}{ Th1 } \\
\hline$I L 1 A$ & $1.22(0.83-1.92) \dagger$ & $4.42(1.90-4.97) \ddagger$ & $1.00(0.73-1.37)$ & .004 \\
\hline$I L 1 B$ & $1.23(0.85-1.94) \dagger$ & $2.51(2.16-2.95) \ddagger$ & $0.98(0.74-1.45)$ & .002 \\
\hline$I F N G$ & $1.26(0.68-2.24)$ & $1.01(0.69-1.25)$ & $0.94(0.78-1.15)$ & .524 \\
\hline$T N F$ & $1.34(1.01-1.84)$ & $1.21(0.68-1.72)$ & $1.02(0.59-1.95)$ & .336 \\
\hline \multicolumn{5}{|l|}{ Th2 } \\
\hline IL4 & $0.90(0.74-1.11)$ & $1.00(0.89-1.50)$ & $0.90(0.82-1.38)$ & .313 \\
\hline IL5 & $1.54(0.90-2.77)$ & $1.34(0.54-1.44)$ & $1.12(0.64-1.54)$ & .101 \\
\hline IL10 & $0.57(0.39-0.83)^{*}$ & $0.56(0.35-1.07)$ & $0.94(0.70-1.68)$ & .032 \\
\hline
\end{tabular}

$* P<.025$ compared with cholelithiasis controls.

$\dagger P<.005$ compared with intestinal failure controls.

$\ddagger P<.008$ between intestinal failure and cholelithiasis controls.

Data are median (interquartile range). RNA expression is expressed after normalization to housekeeping genes as fold change relative to cholelithiasis control subjects. Significance was evaluated for multiple groups by Kruskall-Wallis $\mathrm{H}$ test and for pairs of groups by Mann-Whitney $U$ test. Bolded $P$-values mean that they are statistically significant $(P<.05)$.

Table IV. Comparison between patients with and without periductal $\alpha$-SMA expression at follow-up

\begin{tabular}{|c|c|c|c|}
\hline & $\begin{array}{c}\text { Positive } \alpha-S M A \\
\text { periductal expression }(64 \%)\end{array}$ & $\begin{array}{c}\text { Negative } \alpha-S M A \text { periductal } \\
\text { expression }(36 \%)\end{array}$ & $\mathrm{P}$ value \\
\hline \multicolumn{4}{|l|}{ At portoenterostomy } \\
\hline Age, days & $65(47-84)$ & $50(24-76)$ & .157 \\
\hline Metavir stage (0-4) & $2(2-3)$ & $2(2-3)$ & .275 \\
\hline \multicolumn{4}{|l|}{ At follow-up } \\
\hline Follow-up age, y & $2.8(1.6-4.8)$ & $3.0(2.1-10.6)$ & .234 \\
\hline Metavir stage $(0-4)$ & $3(2-4)$ & $2(1-3)$ & .084 \\
\hline Collagen, grade $(0-4)$ & $2(2-3)$ & $2(1-2)$ & .115 \\
\hline Collagen, area fraction $(\%)$ & $18.2(13.9-24.7)$ & $11.9(7.7-14.0)$ & .031 \\
\hline$\alpha$-SMA, grade $(0-4)$ & $4(1-4)$ & $2(0-2)$ & .015 \\
\hline$\alpha$-SMA, area fraction $(\%)$ & $15.5(11.7-22.5)$ & $11.8(10.0-13.2)$ & .062 \\
\hline COL1A2, fold change & $2.86(1.83-4.46)$ & $2.74(1.13-3.26)$ & .286 \\
\hline ACTA2, fold change & $1.62(1.35-3.26)$ & $1.57(0.66-2.47)$ & .320 \\
\hline PDGFA, fold change & $4.31(2.94-7.28)$ & $2.17(1.32-3.39)$ & .019 \\
\hline Ductal reaction $(\%)$ & $4.2(1.8-10.7)$ & $1.7(0.6-2.2)$ & .010 \\
\hline Bilirubin total, $\mu \mathrm{mol} / \mathrm{L}$ & $12(7-22)$ & $4(3-8)$ & .016 \\
\hline Bilirubin direct, $\mu \mathrm{mol} / \mathrm{L}$ & $6(3-18)$ & $1(1-3)$ & .001 \\
\hline Bile acids total, $\mu \mathrm{mol} / \mathrm{L}$ & $47(25-143)$ & $15(8-23)$ & .002 \\
\hline Alanine aminotransferase, $\mathrm{U} / \mathrm{L}$ & $87(26-115)$ & $25(21-41)$ & .036 \\
\hline APRI $*$ & $1.32(0.56-2.22)$ & $0.43(0.27-1.51)$ & .048 \\
\hline
\end{tabular}

*APRI, [(aspartate aminotransferase $(\mathrm{AST}, \mathrm{U} / \mathrm{L}) / 50) /$ platelet count $(\mathrm{E} 9 / \mathrm{L})] \times 100$.

Data are median (interquartile range). Significance between groups was evaluated by Mann-Whitney $U$ test. Bolded $P$-values mean that they are statistically significant $(P<.05)$.

after SPE, the livers of BA patients continue to overexpress collagen and $\alpha$-SMA, which is associated with enhanced ductal reaction and PDGFA gene expression, but limited proinflammatory cytokine gene expression, compared with fibrotic and nonfibrotic pediatric controls.
Our findings show that molecular signature of liver fibrosis prevails after SPE as the expression of collagen 1 and $\alpha$-SMA persists largely unchanged. Inflammatory response and proinflammatory cytokines may not have a central role in driving fibrogenesis long-term after SPE because portal 
Table V. Comparison between isolated and syndromic BA

\begin{tabular}{|c|c|c|c|}
\hline & $\begin{array}{l}\text { Isolated BA } \\
\mathrm{n}=16\end{array}$ & $\begin{array}{c}\text { Syndromic } B A \\
\mathrm{n}=12\end{array}$ & $\mathrm{P}$ value \\
\hline \multicolumn{4}{|l|}{ At portoenterostomy } \\
\hline Age, d & $64(43-90)$ & $54(39-77)$ & .430 \\
\hline Metavir stage $(0-4)$ & $2(2-3)$ & $2(2-3)$ & .310 \\
\hline \multicolumn{4}{|l|}{ At follow-up } \\
\hline Follow-up age, y & $2.9(2.1-5.2)$ & $4.2(2.0-9.2)$ & .642 \\
\hline Metavir stage $(0-4)$ & $3(2-4)$ & $2(1-2)$ & .019 \\
\hline Portal inflammation $(0-3)$ & $1(1-2)$ & $0(0-1)$ & .028 \\
\hline Collagen, grade $(0-4)$ & $2(2-4)$ & $1.5(0-2)$ & .006 \\
\hline Collagen, area fraction $(\%)$ & $19.6(13.2-29.9)$ & $9.5(6.5-15.9)$ & .014 \\
\hline$\alpha$-SMA, grade $(0-4)$ & $3(2-4)$ & $1(0-2.5)$ & .017 \\
\hline$\alpha$-SMA, area fraction $(\%)$ & $15.7(12.1-22.0)$ & $11.1(9.2-14.9)$ & .028 \\
\hline COL1A2, fold change & $3.02(1.79-4.20)$ & $2.06(1.49-3.47)$ & .456 \\
\hline ACTA2, fold change & $1.50(1.04-3.46)$ & $2.03(1.09-2.63)$ & .493 \\
\hline PDGFA, fold change & $3.74(2.04-5.77)$ & $2.63(1.84-5.94)$ & .571 \\
\hline Ductal reaction (\%) & $3.1(1.8-8.6)$ & $1.9(1.5-4.1)$ & .167 \\
\hline
\end{tabular}

Data are median (interquartile range). Significance between groups was evaluated by Mann-Whitney $U$ test. Bolded $P$-values mean that they are statistically significant $(P<.05)$.

inflammatory cell infiltrate significantly reduced after PE and expression of genes encoding for several Th1 and Th2 cytokines remained unaltered or even lower than in intestinal failure controls with comparable Metavir stage. These observations further suggest that anti-inflammatory therapy may not improve native liver survival in the long-term, although corticosteroid therapy seems to promote clearance of jaundice shortly after PE, when the liver displays signs of active inflammation. ${ }^{26}$

During cholestasis activated HSCs encircle bile ducts, and periductular myofibroblasts form portal-to-portal fibrotic septa. ${ }^{12,27}$ In BA, biliary epithelial cells and cells adjacent to ductal reactions express mesenchymal markers and growth factors consistent with active collagen synthesis, although the origin of these cells forming new bile ductules is unclear. ${ }^{14}$ At PE and at the time of LTx, when patients are often severely cholestatic, $\alpha$-SMA is increasingly expressed around ductular proliferations in portal areas and in fibrous septa. ${ }^{28-32}$ Expression of $\alpha$-SMA correlates with the extent of fibrosis in BA. ${ }^{21,29,30,33,34}$ and increased expression of $\alpha$-SMA at PE predicts impaired outcome. ${ }^{21,29,31,35}$ Accordingly, we found portally concentrated periductal $\alpha$-SMA expression patterns, which tended to persist after SPE. Opposed to none of the controls, all BA patients showed periductal $\alpha$-SMA at PE, but $36 \%$ lost this expression pattern at follow-up. Periductal $\alpha$-SMA associated with progression of fibrosis, expansion of ductal reactions, collagen accumulation, PDGFA expression, and serum bile acid levels. These findings suggest that periductular $\alpha$-SMA expression may be driven by the persisting ductal reaction and essentially contribute to the continuing fibrogenesis after SPE. Further studies addressing connections between bile acid levels, persisting ductal reaction, and liver fibrosis are needed in BA patients to explore the possibility to prevent liver injury by artificial reduction of bile acid synthesis.

Upregulated expression of PDGFA was unique to BA compared with controls, associating with increased collagen and $\alpha$-SMA expression. Platelets, myofibroblasts, vascular endothelial cells and biliary epithelial cells ${ }^{36-39}$ express PDGF, which is the key growth factor in HSC activation and proliferation $^{13,27}$ and possibly in epithelial-tomesencymal transformation. ${ }^{27}$ Previous studies have reported increased expression of PDGFA in BA at the time of PE and LTx ${ }^{36,37,39}$ with a correlation to fibrosis. ${ }^{39}$ Our observations suggest an important role for PDGFA in maintaining active fibrogenesis also after SPE.

In total, $43 \%$ of our patients had structural malformations typically associated with BA, suggesting that these patients had a developmental origin of the disease. ${ }^{40,41}$ These syndromic patients demonstrated less deterioration in Metavir fibrosis stage, greater decrease in portal inflammation, and lower liver expression of collagen and $\alpha$-SMA than patients with isolated BA. Although this finding will need to be confirmed in larger patient samples, it suggests that after SPE, fibrosis may be less progressive and potentially more responsive to interventions in syndromic patients. Based on these observations, patients should be stratified 
for isolated and syndromic disease form in future interventional studies.

Our study had limitations, which include small sample size, cross-sectional design, and relatively large age variation, which provides merely associations than proof of causality. Due to the limited availability of liver specimens for obvious reasons, our control material was obtained from several different sources. Strengths of this study are inclusion of diseased and "healthy" controls and comprehensive assessment of liver fibrosis and inflammation in relation to clinical data.

In conclusion, after SPE and resolution of cholestasis, molecular signature of active fibrogenesis prevailed in the livers of BA patients. Persisting fibrogenesis was associated with a limited inflammatory response, which was even less pronounced than in patients with intestinal failure associated liver fibrosis, suggesting that anti-inflammatory therapy might not be the most promising approach to improve the long-term native liver survival in BA. The enhanced periductal smooth muscle expression associated with expansion of the ductal proliferation, progression of fibrosis, RNA expression of $P D G F A$, and circulating bile acid concentrations, suggesting that potential of pharmacological reduction of bile acid levels for hepatocyte protection after SPE should be addressed in future studies.

\section{REFERENCES}

1. Sokol RJ, Mack C, Narkewicz MR, Karrer FM. Pathogenesis and outcome of biliary atresia: current concepts. J Pediatr Gastroenterol Nutr 2003;37:4-21.

2. Perlmutter DH, Shepherd RW. Extrahepatic biliary atresia: a disease or a phenotype? Hepatology 2002;35:1297-304.

3. Feldman AG, Mack CL. Biliary atresia: clinical lessons learned. J Pediatr Gastroenterol Nutr 2015;61:167-75.

4. Petersen C, Davenport M. Aetiology of biliary atresia: what is actually known? Orphanet J Rare Dis 2013;8:128.

5. Bessho K, Bezerra JA. Biliary atresia: will blocking inflammation tame the disease? Ann Rev Med 2011;62:171-85.

6. Lampela H, Ritvanen A, Kosola S, Koivusalo A, Rintala R, Jalanko H, et al. National centralization of biliary atresia care to an assigned multidisciplinary team provides highquality outcomes. Scand J Gastroenterol 2012;47:99-107.

7. Lampela H, Kosola S, Heikkila P, Lohi J, Jalanko H, Pakarinen MP. Native liver histology after successful portoenterostomy in biliary atresia. J Clin Gastroenterol 2014;48:721-8.

8. Gautier M, Valayer J, Odievre M, Alagille D. Histological liver evaluation 5 years after surgery for extrahepatic biliary atresia: a study of 20 cases. J Pediatr Surg 1984;19:263-8.

9. Hirschfield GM, Mason A, Luketic V, Lindor K, Gordon SC, Mayo M, et al. Efficacy of obeticholic acid in patients with primary biliary cirrhosis and inadequate response to ursodeoxycholic acid. Gastroenterol 2015;148:751-761.e8.

10. Neuschwander-Tetri BA, Loomba R, Sanyal AJ, Lavine JE, Van Natta ML, Abdelmalek MF, et al. Farnesoid X nuclear receptor ligand obeticholic acid for non-cirrhotic, non-alcoholic steatohepatitis (FLINT): a multicentre, randomised, placebo-controlled trial. Lancet 2015;385:956-65.

11. Verkade HJ, Bezerra JA, Davenport M, Schreiber RA, MieliVergani G, Hulscher JB, et al. Biliary atresia and other cholestatic childhood diseases: advances and future challenges. J Hepatol 2016;65:631-42.

12. Friedman SL. Hepatic stellate cells: protean, multifunctional, and enigmatic cells of the liver. Physiol Rev 2008; 88:125-72.

13. Bataller R, Brenner DA. Hepatic stellate cells as a target for the treatment of liver fibrosis. Semin Liver Dis 2001;21:437-51.

14. Diaz R, Kim JW, Hui JJ, Li Z, Swain GP, Fong KS, et al. Evidence for the epithelial to mesenchymal transition in biliary atresia fibrosis. Hum Pathol 2008;39:102-15.

15. Fabris L, Brivio S, Cadamuro M, Strazzabosco M. Revisiting epithelial-to-mesenchymal transition in liver fibrosis: clues for a better understanding of the "reactive" biliary epithelial phenotype. Stem Cells Int 2016;2016:2953727.

16. Mavila N, James D, Shivakumar P, Nguyen MV, Utley S, Mak K, et al. Expansion of prominin-1-expressing cells in association with fibrosis of biliary atresia. Hepatology 2014;60: 941-53.

17. Santos JL, Kieling CO, Meurer L, Vieira S, Ferreira CT, Lorentz A, et al. The extent of biliary proliferation in liver biopsies from patients with biliary atresia at portoenterostomy is associated with the postoperative prognosis. J Pediatr Surg 2009;44:695-701.

18. Bateman AC, Hubscher SG. Cytokeratin expression as an aid to diagnosis in medical liver biopsies. Histopathology 2010;56:415-25.

19. Kerola A, Lampela H, Lohi J, Heikkila P, Mutanen A, Hagstrom J, et al. Increased MMP-7 expression in biliary epithelium and serum underpins native liver fibrosis after successful portoenterostomy in biliary atresia. J Pathol Clin Res 2016;2:187-98.

20. Longo-Santos LR, Teodoro WR, de Mello ES, Velosa AP, Parra ER, Capelozzi VL, et al. Early type I collagen deposition is associated with prognosis in biliary atresia. J Pediatr Surg 2016;51:379-85.

21. Suominen JS, Lampela H, Heikkila P, Lohi J, Jalanko H, Pakarinen MP. Myofibroblastic cell activation and neovascularization predict native liver survival and development of esophageal varices in biliary atresia. World J Gastroenterol 2014;20:3312-9.

22. Friedman SL. Mechanisms of hepatic fibrogenesis. Gastroenterol 2008;134:1655-69.

23. Kim SY, Seok JY, Han SJ, Koh H. Assessment of liver fibrosis and cirrhosis by aspartate aminotransferase-to-platelet ratio index in children with biliary atresia. J Pediatr Gastroenterol Nutr 2010;51:198-202.

24. Davenport M, Tizzard SA, Underhill J, Mieli-Vergani G, Portmann B, Hadzic N. The biliary atresia splenic malformation syndrome: a 28-year single-center retrospective study. J Pediatr 2006;149:393-400.

25. Olynyk JK, Yeoh GC, Ramm GA, Clarke SL, Hall PM, Britton RS, et al. Gadolinium chloride suppresses hepatic oval cell proliferation in rats with biliary obstruction. Am J Pathol 1998;152:347-52.

26. Chen Y, Nah SA, Chiang L, Krishnaswamy G, Low Y. Postoperative steroid therapy for biliary atresia: Systematic review and meta-analysis. J Pediatr Surg 2015;50:1590-4.

27. Hernandez-Gea V, Friedman SL. Pathogenesis of liver fibrosis. Annu Rev Pathol 2011;6:425-56.

28. Lamireau T, Le Bail B, Boussarie L, Fabre M, Vergnes P, Bernard O, et al. Expression of collagens type I and IV, 
osteonectin and transforming growth factor beta- 1 (TGFbeta1) in biliary atresia and paucity of intrahepatic bile ducts during infancy. J Hepatol 1999;31:248-55.

29. Dong R, Luo Y, Zheng S. alpha-SMA overexpression associated with increased liver fibrosis in infants with biliary atresia. J Pediatr Gastroenterol Nutr 2012;55:653-6.

30. Murata K, Kamata Y, Munakata H, Sugai M, Sasaki M. Immunohistochemical study on liver fibrosis in biliary atresia. Hepatogastroenterol 2008;55:179-83.

31. Shirahase I, Ooshima A, Tanaka K, Yamabe H, Inomata Y, Ozawa K. Immunohistochemical demonstration of collagen types III and IV and myofibroblasts in the liver of patients with biliary atresia. J Pediatr Surg 1994;29:639-44.

32. Farrington C, Novak D, Liu C, Haafiz AB. Immunohistochemical localization of transforming growth factor beta-1 and its relationship with collagen expression in advanced liver fibrosis due to biliary atresia. Clin Exp Gastroenterol 2010;3:185-91.

33. Xiao Y, Zhou Y, Chen Y, Zhou K, Wen J, Wang Y, et al. The expression of epithelial-mesenchymal transition-related proteins in biliary epithelial cells is associated with liver fibrosis in biliary atresia. Pediatr Res 2015;77:310-5.

34. Ramm GA, Nair VG, Bridle KR, Shepherd RW, Crawford DH. Contribution of hepatic parenchymal and nonparenchymal cells to hepatic fibrogenesis in biliary atresia. Am J Pathol 1998;153:527-35.
35. Shteyer E, Ramm GA, Xu C, White FV, Shepherd RW. Outcome after portoenterostomy in biliary atresia: pivotal role of degree of liver fibrosis and intensity of stellate cell activation. J Pediatr Gastroenterol Nutr 2006;42:93-9.

36. Malizia G, Brunt EM, Peters MG, Rizzo A, Broekelmann TJ, McDonald JA. Growth factor and procollagen type I gene expression in human liver disease. Gastroenterol 1995; 108:145-56.

37. Faiz Kabir Uddin Ahmed A, Ohtani H, Nio M, Funaki N, Iwami D, Kumagai S, et al. In situ expression of fibrogenic growth factors and their receptors in biliary atresia: comparison between early and late stages. J Pathol 2000;192:73-80.

38. Wallace K, Burt AD, Wright MC. Liver fibrosis. Biochem J 2008;411:1-18.

39. Cofer ZC, Cui S, EauClaire SF, Kim C, Tobias JW, Hakonarson H, et al. Methylation microarray studies highlight PDGFA expression as a factor in biliary atresia. PLoS One 2016;11:e0151521.

40. Carmi R, Magee CA, Neill CA, Karrer FM. Extrahepatic biliary atresia and associated anomalies: etiologic heterogeneity suggested by distinctive patterns of associations. Am J Med Genet 1993;45:683-93.

41. Schwarz KB, Haber BH, Rosenthal P, Mack CL, Moore J, Bove K, et al. Extrahepatic anomalies in infants with biliary atresia: results of a large prospective North American multicenter study. Hepatology 2013;58:1724-31.

Surgery is abstracted and/or indexed in Index Medicus, Science Citation Index, Current Contents/ Clinical Medicine, Current Contents/Life Sciences, and MEDLINE.

This Journal has been registered with Copyright Clearance Center, Inc, 222 Rosewood Dr, Danvers, MA 01923. Consent is given for the copying of articles for personal or internal use of specific clients. This consent is given on the condition that the copier pay directly to the Center the per-copy fee stated on the first page of each article for copying beyond that permitted by US Copyright Law. This consent does not extend to other kinds of copying, such as for general distribution, resale, advertising and promotional purposes, or for creating new collective works. All inquiries regarding copyrighted material from this publication other than those that can be handled through Copyright Clearance Center should be directed to Journals Permission Department, Elsevier Inc, 3521 Riverport Lane, Maryland Heights, MO 63043; (314) 447-8871 